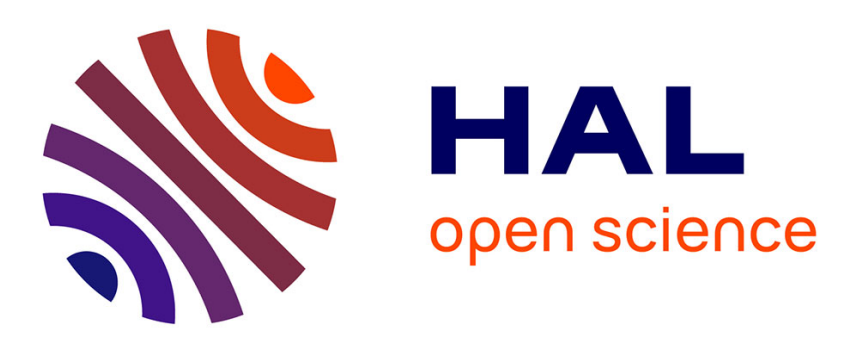

\title{
Analysis of Fractured Samples with Digital Volume Correlation
}

\author{
François Hild, Jean-Yves Buffière, Anthony Gravouil, Nathalie Limodin, \\ Julien Réthoré, Stéphane Roux, Wolfgang Ludwig
}

\section{To cite this version:}

François Hild, Jean-Yves Buffière, Anthony Gravouil, Nathalie Limodin, Julien Réthoré, et al.. Analysis of Fractured Samples with Digital Volume Correlation. Annual Conference on Experimental and Applied Mechanics, Jun 2010, Indianapolis, United States. pp.327-330, 10.1007/978-1-4419-97968_42. hal-01668796

\section{HAL Id: hal-01668796 https://hal.science/hal-01668796}

Submitted on 27 Apr 2021

HAL is a multi-disciplinary open access archive for the deposit and dissemination of scientific research documents, whether they are published or not. The documents may come from teaching and research institutions in France or abroad, or from public or private research centers.
L'archive ouverte pluridisciplinaire HAL, est destinée au dépôt et à la diffusion de documents scientifiques de niveau recherche, publiés ou non, émanant des établissements d'enseignement et de recherche français ou étrangers, des laboratoires publics ou privés. 


\title{
Analysis of Fractured Samples with Digital Volume Correlation
}

\author{
F. Hild, ${ }^{a}$ J-Y. Buffière, ${ }^{b}$ A. Gravouil, ${ }^{c}$ N. Limodin, ${ }^{b}$ J. Réthoré, ${ }^{c}$ S. Roux, ${ }^{a}$ W. Ludwig ${ }^{b, d}$ \\ aLMT-Cachan, ENS Cachan / CNRS / Université Paris 6 / PRES UniverSud Paris, \\ 61 avenue du Président Wilson, F-94235 Cachan Cedex, France \\ Email: hild@Imt.ens-cachan.fr \\ ${ }^{b}$ MATEIS, Université de Lyon, INSA-Lyon / CNRS, Villeurbanne, France \\ ${ }^{\complement}$ LaMCoS, Université de Lyon INSA-Lyon / CNRS, Villeurbanne, France \\ ESRF, Grenoble, France
}

\begin{abstract}
Synchrotron X-ray tomography was used to monitor in situ three dimensional (3D) fatigue crack propagation in a nodular graphite cast iron. Direct image analysis allows for the retrieval of the successive positions of the crack front, and the detection of local crack retardation, while volume correlation enables for the measurement of displacement fields in the bulk of the specimen. Stress Intensity Factors (SIF) are extracted from the measured displacement fields. It is possible to link the non propagation of a crack with crack closure in COD maps or with a local value of the measured SIF range.
\end{abstract}

\section{INTRODUCTION}

The availability of third generation synchrotrons has fostered the development of high resolution (voxel size around $1 \mu \mathrm{m}$ ) X-ray micro-tomography in the last 15 years [1]. A spatial resolution close to that of an optical microscope can now be achieved in 3D that re-opens wide areas of research. One of those areas is the characterization of three dimensional fatigue crack propagation.

In this work we focus on the effect of closure on 3D crack propagation. 3D displacement fields, COD maps, and SIFs have been obtained in situ by combining Digital Volume Correlation (DVC) and synchrotron X-ray tomography at different stages of fatigue life [2]. This complete 3D crack characterization in combination with image analysis and post-failure topography measurements allows for an interpretation of crack propagation / arrest. It is shown that a non uniform closure level along the crack front induces asymmetric crack arrest / propagation.

\section{MATERIAL AND METHODS}

The material studied herein is a ferritic nodular graphite cast iron (Fe - 3.4C - 2.6Si - 0.05Mg - 0.19Mn wt.\%) containing a uniform distribution of nearly spherical graphite nodules (average diameter: $50 \mu \mathrm{m}$ ). The graphite nodules are easily imaged by tomography and used as natural markers for volume correlation of the $3 \mathrm{D}$ reconstructed images.

The tomography experiment was performed on ID19 beamline at the European Synchrotron Radiation Facility (ESRF) in Grenoble, France. A specially designed fatigue machine allowing for in situ loading and high frequency cycling of the specimens was used [3], see Figure 1. Small hourglass pre-cracked fatigue samples cut from larger specimens were used (see Reference [2] for a detailed description of the experiment). A $5.06 \mu \mathrm{m}$ voxel size was chosen. This value, which is one order of magnitude larger than the best resolution 
available at ID19, is much smaller than the graphite nodule average size in order to allow for good quality images to be obtained while it is also large enough for the size of the region of interest, focused around the crack, to be only $340 \times 340 \times 512$ voxels in size. This limited data size enabled for DVC measurements to be performed on line during the tomography experiment.

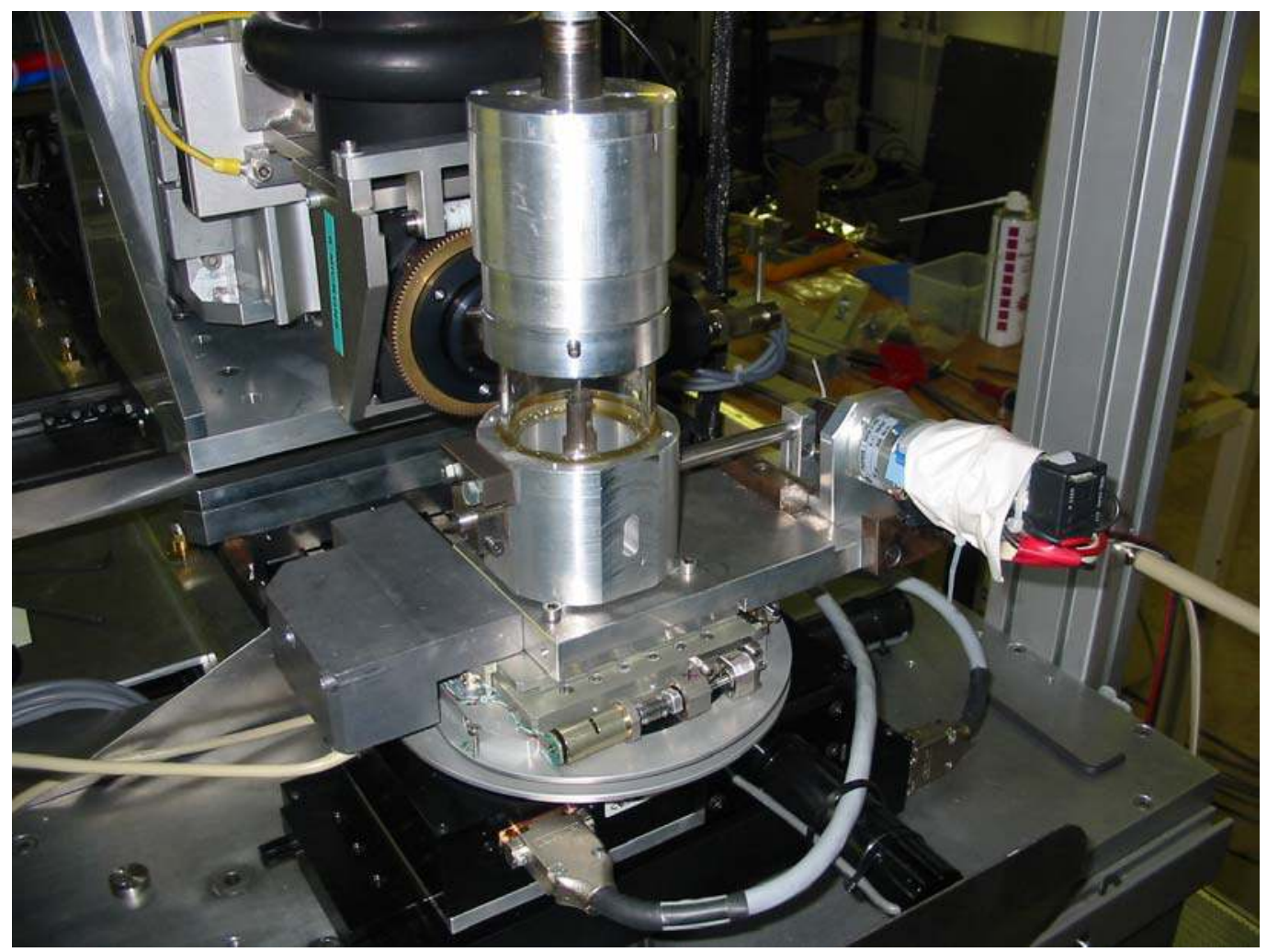

Figure 1. Experimental setup to perform in situ experiments.

At the beginning of the experiments scans were acquired at intermediate loading steps ranging between a minimum and a maximum load $(R=0.1)$. Then during the in situ fatigue experiment, scans were recorded at different time intervals with the specimen held under maximum load. When crack growth was detected in these images, another complete loading / unloading sequence was recorded. The fatigue experiment was conducted until the unbroken ligament became too short for further crack propagation.

\section{DIGITAL VOLUME CORRELATION}

3D displacements of any voxel in the reconstructed 3D volume are assessed by using a volume correlation technique. The principle of DVC is to analyze two images of the same specimen under different loading conditions, and to determine the displacement field in the bulk of the specimen by searching for the best match between the images. In the present case, 3D reconstructed volumes are considered, and 8-node cubic elements defined on a 3D mesh (tri-linear functions of $x, y$ and $z$ ) are chosen (it is designated as C8-DVC [4]).

A Region Of Interest of $288 \times 288 \times 288$ voxels was centered in the original 3D image. Elements with a 16voxel edge were chosen as a good compromise between displacement uncertainty and spatial resolution of the measured displacement fields. For the selected element size, the displacement uncertainty was assessed to be about 0.04 voxel [5].

For a given loading / unloading cycle, correlation was performed between the image obtained at the minimum load of the current cycle and that at the load for which the displacement field was sought. However, for the images that were obtained at different time intervals at the maximum load of a given cycle only, using the reference image of the previous loading cycle was thought to be accurate enough, provided that the crack growth remained limited in the interval.

Due to the presence of the crack, the image obtained under higher load, i.e. the deformed image, cannot be perfectly matched to the reference image once it has been corrected for by the measured displacement field. The difference is the residual error that directly provides a 3D image of the crack surface [2]. Measurement of 
the SIF along the crack front was carried out using a method introduced by Hamam et al. [6] and adapted to 3D images [7]. The residual error is used to retrieve the crack position while the 3D displacement fields obtained with DVC are fitted in each plane orthogonal to the crack front with relevant mechanical solutions in order to extract $K_{I}, K_{I I}$ and $K_{I I I}$ SIF values along the crack front [2].

\section{RESULTS AND ANALYSIS}

In the specimen investigated, the crack has initially a fairly constant length throughout the sample thickness (Figure 2). However in spite of this limited variation in crack length, the measured SIF value increased in a markedly different way from the "short" to the "long" crack side (10 to $15 \mathrm{MPa} \sqrt{\mathrm{m}}$ respectively). During the first fatigue cycles, this large variation in $\Delta K_{l}$ along the crack front resulted in a large variation in crack growth rates with a crack that grew rapidly on the long crack side, while it was pinned on the short crack side where the $\Delta K_{l}$ value is locally below the crack growth threshold $(\sim 10 \mathrm{MPa} \sqrt{\mathrm{m}})$. As shown in Figure 2 , the crack propagation required 3,000 cycles to start on the short crack side. This corresponded to a local value of about $12 \mathrm{MPa} \sqrt{\mathrm{m}}$ for $\Delta K_{\text {, }}$, i.e. a value close to that used for fatigue pre-cracking. Then, the difference in crack growth rates between both sides of the specimen progressively reduced.

An analysis of crack topography was performed to assess the possible influence of the roughness of the crack surfaces on crack propagation. After the fatigue tests, the specimens were broken in bending to allow for their analysis in a laser profilometer.

This analysis revealed a significant step of $85-\mu \mathrm{m}$ in height, i.e. larger than the average size of the graphite nodules, on the short crack side. This step was inherited from the larger pre-cracked sample and the reasons for its occurrence could not be guessed from the observation of the microstructure inside the small tomography sample. However, it is clear that this asperity affected the propagation of the crack as there is a strong correlation between the crack front region where the crack was arrested for almost 3,000 cycles and this bifurcation in the crack path.

It is expected that the presence of the step in the crack plane induces mode II / mode III displacements with corresponding non-zero $K_{/ I} / K_{/ I}$ values that have a shielding effect on mode I opening.
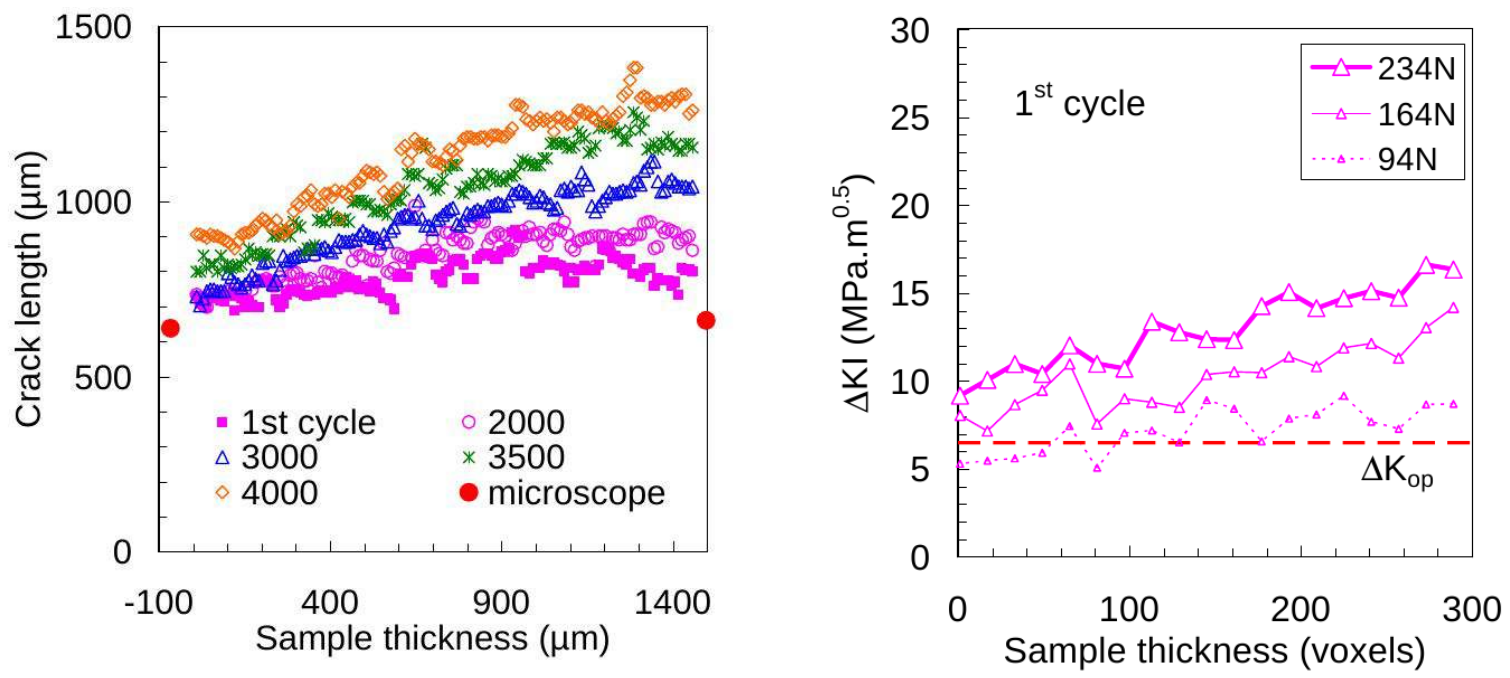

Figure 2. Crack front location as a function of fatigue cycles (left). Variation of the mode I stress intensity factor along the crack front for the first fatigue cycle for three different levels (right).

\section{ACKNOWLEDGMENTS}

This work was funded under the grant ANR-09-BLAN-0009-01 (RUPXCUBE Project). It was also made possible by an ESRF grant for the experiment MA-501 on beamline ID19.

\section{REFERENCES}

[1] S. R. Stock (2008) Recent advances in X-Ray microtomography applied to materials. Int. Mat. Rev. 53 [3], 129-181. 
[2] J. Rannou, N. Limodin, J. Réthoré, A. Gravouil, W. Ludwig, M.-C. Baïetto-Dubourg, J.-Y. Buffière, A. Combescure, F. Hild and S. Roux (2010) Three dimensional experimental and numerical multiscale analysis of a fatigue crack. Comp. Meth. Appl. Mech. Eng. 199, 1307-1325.

[3] J.-Y. Buffière, E. Maire, J. Adrien, J.-P. Masse and E. Boller (2010) In Situ Experiments with X ray Tomography: an Attractive Tool for Experimental Mechanics. Exp. Mech. 50 [3], 289-305.

[4] S. Roux, F. Hild, P. Viot and D. Bernard (2008) Three dimensional image correlation from X-Ray computed tomography of solid foam. Comp. Part A 39 [8], 1253-1265.

[5] N. Limodin, J. Réthoré, J.-Y. Buffière, F. Hild, S. Roux, W. Ludwig, J. Rannou and A. Gravouil (2010) Influence of closure on the 3D propagation of fatigue cracks in a nodular cast iron investigated by X-ray tomography and 3D Volume Correlation. Acta Mat., doi:10.1016/j.actamat.2010.01.024.

[6] R. Hamam, F. Hild and S. Roux (2007) Stress intensity factor gauging by digital image correlation: Application in cyclic fatigue. Strain 43, 181-192.

[7] N. Limodin, J. Réthoré, J.-Y. Buffière, A. Gravouil, F. Hild and S. Roux (2009) Crack closure and stress intensity factor measurements in nodular graphite cast iron using 3D correlation of laboratory $X$ ray microtomography images. Acta Mat. 57 [14], 4090-4101. 